\title{
Drawing Properties and Physical Properties of Ultrahigh-Molecular-Weight Polyethylene Swollen in Mixed Solvent
}

\author{
Hitoshi Fujimatsu, ${ }^{\dagger}$ Yong Seup Kim, Hiroaki MatsuZaKi, Atsushi NaKamura, \\ Hisanao USAMI, and Shinji OGASAWARA \\ Department of Fine Materials Engineering, Faculty of Textile Science and Technology, \\ Shinshu University, 3-15-1 Tokida, Ueda, Nagano 386-8567, Japan
}

(Received November 21, 2000; Accepted August 20, 2001)

\begin{abstract}
We report new conditions for obtaining high-strength and high-modulus polyethylene using the swelldrawing process which was introduced by Mackley and Solbai [Polymer, 28, 1115 (1987)]. Cyclohexane-toluene mixture was used to allow polyethylene with $M_{\mathrm{w}}$ of $1.75 \times 10^{6}$ to swell significantly at relatively low temperature. We found that a dumbbell-shaped polyethylene specimen swelled under stress gained higher drawability in subsequent drawing processes. It was confirmed that in a polyethylene specimen swelled and elongated under an optimal stress, the fibrillar textures were oriented without recrystallization in the direction of elongation. The specimen showed highest draw ratio when the solvent in the swollen polyethylene was reduced to $30 \%$ of the polyethylene in weight. Under these conditions a maximum tensile strength of $3.5 \mathrm{GPa}$ and modulus of $120 \mathrm{GPa}$ were achieved. These values are greater than those for the fiber prepared by Mackley and Solbai [Polymer, 28, 1115 (1987)] who used polyethylene with molecular weight greater than $10^{6}$. The present results show that the improved swell-drawing method, where polyethylene specimen swelled and elongated under appropriate stress is drawn, can be used for the production of high-strength and high-modulus fiber from ultra-high molecular weight polyethylene. The result suggests the applicability of the method for polyethylene of much larger molecular weight.

KEY WORDS High-Strength and High-Modulus Polyethylene Fiber / Swelling / Ultra Drawing / Mixed Solvent / Toluene / Cyclohexane /
\end{abstract}

A number of methods have been developed and investigated to produce a high-strength and high-modulus polyethylene fiber; they include surface-growth method, single-crystal drawing method, gel-spinning method, and gel-like spherulite press method. ${ }^{2-10}$ In these methods, high-strength and high-modulus polyethylene fibers have been produced by reducing intermolecular and intramolecular entanglements of polyethylene chains. Mackley and Solbai ${ }^{1}$ have reported a so-called "swell-drawing method". They demonstrated that swelling can be used to draw ultrahigh molecular weight polyethylene (UHMWPE), and achieved draw ratios in excess of 30 . The resulting fiber had Young's modulus exceeding $100 \mathrm{GPa}$ and tensile strength over $2.4 \mathrm{GPa} .{ }^{1,11}$ This method makes it possible to draw UHMWPE without dissolving it, and hence provides us with an approach different from the conventional ones. If general techniques for improving the method and leading to fibers with even better characteristics can be developed, an industrial application of the method will become realistic. The method is valuable because it is applicable to polyethylene with much higher molecular weight. It is well known that tensile strength and modulus of polyethylene fibers, irrespective of the method of preparation, depend on the molecular weight of the polyethylene used. ${ }^{12}$
Accordingly, it is expected that the application of the method to polyethylene with higher molecular weight leads to fibers of higher performance.

In the present paper we examine conditions for the swell-drawing method that contribute to the enhancement of the performance of polyethylene fiber. We focus our attention on swelling that is particularly important for introducing a solvent into the polyethylene. Another important aspect of swelling is that it reduces entanglements within the polyethylene. Thus, it is expected, the higher the degree of swelling, the greater the reduction in entanglements in the polyethylene. First we selected solvents that allowed a higher swelling ratio at a relatively low temperature. But higher swelling induced merely the drawing ratio and the tensile strength comparable to those of Mackley et al. ${ }^{1}$ Therefore, we examined in detail a possibility of greater reduction in entanglements within the swollen polyethylene resulting from a stress applied to the polyethylene. We also examined the effect of residual solvent used for swelling on subsequent drawing as well as the swelling conditions leading to ultradrawing. 
Table I. Boiling points (bp) and solubility parameters (SP) of solvents employed

\begin{tabular}{lrl}
\hline $\begin{array}{l}\text { Binary or single } \\
\text { solvent }\end{array}$ & $\mathrm{bp} /{ }^{\circ} \mathrm{C}$ & $\mathrm{SP}$ \\
\hline $\begin{array}{l}\text { Cyclohexane } \\
\text { Toluene }\end{array}$ & 80.7 & 8.2 \\
Cyclohexane & 110.6 & 8.9 \\
o-Xylene & 80.7 & 8.2 \\
Cyclohexane & 138.4 & 8.8 \\
Ethylbenzene & 136.2 & 8.2 \\
Decalin & 189.0 & 7.3 \\
Toluene & 110.6 & 8.9 \\
\hline
\end{tabular}



Figure 1. Temperature program for molding a polyethylene sheet.

\section{EXPERIMENTAL}

\section{Materials}

The polyethylene used in the present study was UHMWPE, supplied from Showa Denko Co., with the weight average molecular weight approximately $1.75 \times$ $10^{6}$. The solvents used for the swelling of UHMWPE were cyclohexane, toluene, $o$-xylene, ethylbenzene and decaline of Wako reagent grade. They were used alone or mixed as shown in Table I.

\section{Method}

\section{Process for the Drawability Material}

Polyethylene sheets were molded by a vacuum press apparatus of Shibayama Scientific Machinery Co. (Japan), which was controlled according to the temperature program shown in Figure 1. The molded sheets were cut into dumbbell-shaped specimens with a gauge length of $6 \mathrm{~mm}$ and a width of $1 \mathrm{~mm}$. Swelling was carried out by immersing the specimens in the solvents in

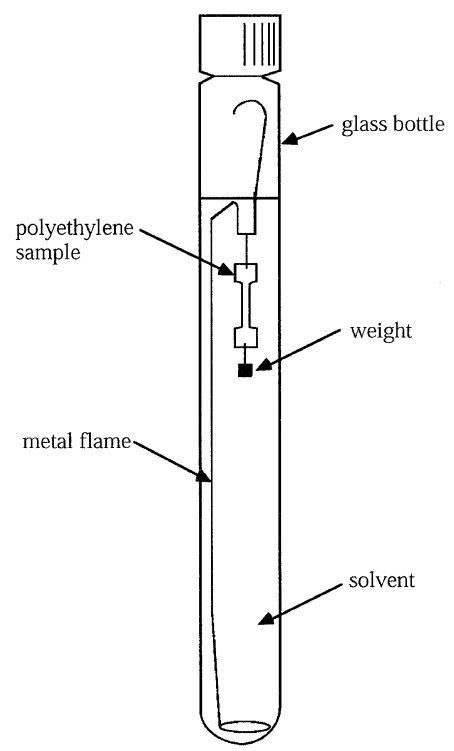

Figure 2. Schematic representation of the glass bottle used for swelling.

a test-tube with a screw cap (Figure 2). The test-tubes were placed in a poly(ethylene glycol) bath to keep the temperature constant. To induce elongation of the swelling specimen, which we call pre-drawing, varying weights were attached to the bottoms of the substrates. The values of the weights were corrected for the buoyancies due to the solvents. The net weight divided by the cross-sectional area of the specimen is defined as the tensile stress applied in swelling. Swelling behavior was observed by monitoring the lower end of the specimen using a cathetometer. The ratio $L / L_{0}$ of the swollen length $L$ to the initial length $L_{0}$ of the specimen is defined as the pre-draw ratio.

The test-tube containing the swollen specimen was quenched to $-50^{\circ} \mathrm{C}$ in order to maintain the lowentanglement state induced by the swelling. The specimen was then exposed to the atmosphere at $20^{\circ} \mathrm{C}$ to dry for a specific time. To prevent shrinkage and structural changes in the specimen during the drying process, both ends of the specimen were fixed.

Drawing was carried out on a hand-made apparatus that consisted of a rail and a pair of clamps. The specimen is fixed between the clamps. One of the clamps can slides on the rail while the other is fixed. The movable clamp is pulled by a motor at a fixed speed to draw the specimen. The whole apparatus is immersed in a poly(ethylene glycol) bath in order to maintain a constant temperature within $\pm 1{ }^{\circ} \mathrm{C}$.

The draw ratio $\lambda$ of the swell-drawn specimen is defined by

$$
\lambda=\left(L^{\prime}-L_{0}^{\prime}\right) L_{0}^{\prime}
$$

where $L_{0}^{\prime}$ is the initial distance between clamps and $L^{\prime}$ is the distance after uniaxial drawing. 


\section{Measurement of Mechanical Properties}

The tensile strength and Young's modulus of the swell-drawn materials were measured at room temperature. Measurements were carried out on specimens of initial length $300 \mathrm{~mm}$ at a crosshead speed of $10 \mathrm{~mm} \mathrm{~min}^{-1}$. The cross-sectional area of each specimen was measured with an optical microscope.

\section{Polarized FT-IR Measurement}

To examine the orientation of the swell-elongated specimens, polarized FT-IR was used to estimate the dichroic ratio of the absorption band at $1894 \mathrm{~cm}^{-1}$ assigned to the crystalline $\mathrm{CH}_{2}$ rocking vibration. ${ }^{13-15}$

\section{SEM Observation}

SEM was used to examine the structural differences in the specimens swollen under different stresses. SEM specimens were prepared by depositing gold in vacuum below $10^{-5}$ Torr on freeze-dried specimens treated with fuming nitric acid for $8 \mathrm{~h}$. SEM images were observed with an AKASHI ALPHA-30 scanning electron microscope.

\section{RESULTS AND DISCUSSION}

\section{Selection of Swelling Solvent}

Various solvents, including decaline, xylene, and tetraline, have been commonly used for gelling and swelling polyethylene. Considering the process of removing solvents after swelling, these solvents are not necessarily appropriate. An ideal solvent would be the one with a low boiling temperature and with high swelling ratio at a low temperature. As no single solvent was found with such characteristics, mixed solvents were explored in the present study. They were prepared by mixing two solvents, one with higher and the other with lower solubility parameter than 8.2 for polyethylene. The boiling points and solubility parameters of the mixed solvents are listed in Table I. The swelling characteristic of polyethylene in these solvents mixed in $1: 1$ volume ratio was examined. The results are tabulated in Table II along the results obtained with single solvents. Of all solvent systems examined, the cyclohexane-toluene and cyclohexane$o$-xylene systems were found to swell high-density polyethylene quickly at a relatively low temperature. Based on these results, a cyclohexane-toluene mixture was selected as the solvent. Examining the results of carefully swelling experiments carried out using solvents of varying mixing ratios, cyclohexane-toluene mixture of volume ratio of $9.5: 0.5$ was determined to be optimal. All subsequent experiments were carried out in the cyclohexane-toluene mixture of this volume

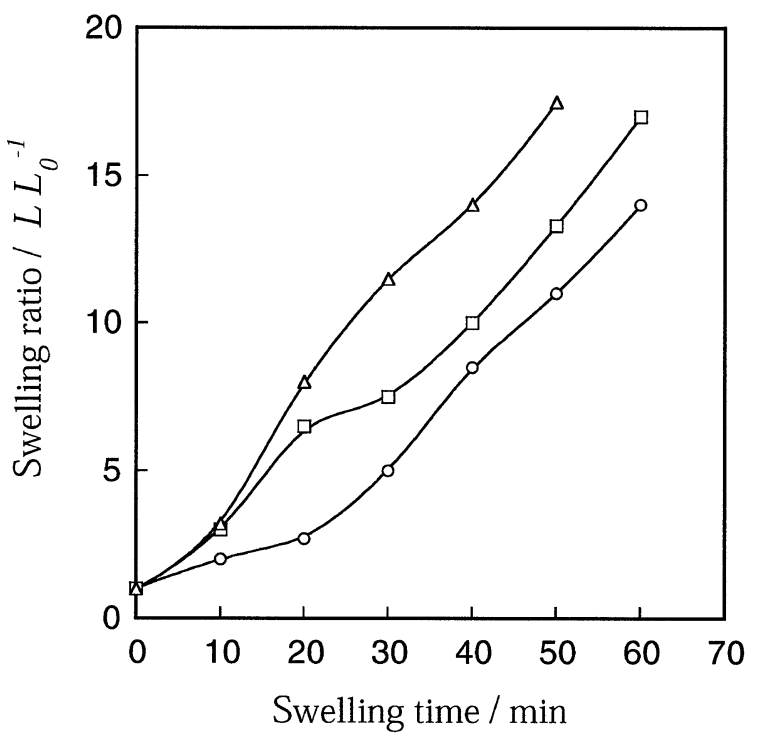

Figure 3. Swelling behavior for polyethylene specimens swollen freely in cyclohexane-toluene mixture at volume ratios of $0.5 / 9.5$ at different temperatures: $103^{\circ} \mathrm{C}(\bigcirc), 104^{\circ} \mathrm{C}(\square), 105^{\circ} \mathrm{C}$ $(\triangle)$.

ratio.

\section{Swelling Behavior without Stress}

The swelling behavior for dumbbell-shaped polyethylene specimens in the cyclohexane-toluene mixture was examined at $103^{\circ} \mathrm{C}, 104^{\circ} \mathrm{C}$, and $105^{\circ} \mathrm{C}$. The results are shown in Figure 3. At $103^{\circ} \mathrm{C}$, although the swelling rate is initially low, it begins to increase after approximately $20 \mathrm{~min}$. At $104^{\circ} \mathrm{C}$, although the initial rate is high, the rate reduces once in the course of the swelling. At $105^{\circ} \mathrm{C}$, the swelling ratio increases smoothly with the swelling time.

\section{Weight Loss in Swelling}

Mackley and Solbai ${ }^{1}$ pointed out that it was important for subsequent drawing that polyethylene was swollen without significant weight loss, and reported that sample weight loss was generally less than $5 \%$. In our system, the weight loss of the polyethylene specimen during the swelling process was recorded every $10 \mathrm{~min}$. The results are shown in Figure 4 . At $103^{\circ} \mathrm{C}$, the weight loss is less than $1 \%$ in the initial $50 \mathrm{~min}$, but then increases rapidly beyond that time. At $104^{\circ} \mathrm{C}$, it begins to increase rapidly after a short swelling time, and reaches above $5 \%$ in approximately $50 \mathrm{~min}$. As the temperature increases, the point at which a weight loss begins to increase rapidly shifts towards the origin. Comparing these results with the swelling behaviors of Figure 3, the rapid increase of the weight loss is found to occur when the swelling ratio reaches 7 to 12 .

From these results, the swelling temperature and time necessary to obtain a relatively high swelling ratio with minimal weight loss were determined to be $104^{\circ} \mathrm{C}$ 
Table II. Swelling features of polyethylene sheets in a variety of binary and single solvent systems

\begin{tabular}{lcccccc}
\hline \multicolumn{1}{c}{$\begin{array}{c}\text { Binary solvent system } \\
\text { (volume ratio }=1: 1)\end{array}$} & 100 & 101 & 102 & 103 & 104 & 105 \\
\cline { 2 - 7 } Cyclohexane-toluene & +++ & +++ & ++++ & +++++ & +++++ & +++++ \\
Cyclohexane- $o$-xylene & ++ & ++ & ++ & ++++ & +++++ & +++++ \\
Cyclohexane-ethylbenzene & + & + & ++ & +++ & ++++ & ++++ \\
Decalin & - & - & ++ & +++ & ++++ & ++++ \\
Toluene & - & - & + & ++ & +++ & +++ \\
$o$-Xylene & - & - & + & + & ++ & ++ \\
\hline
\end{tabular}

-: Unnoticeable, +: barely noticeable, ++ : noticeable, +++ : very noticeable, ++++ : very high noticeable, +++++ : unrecognizable polymer-solvent interface.

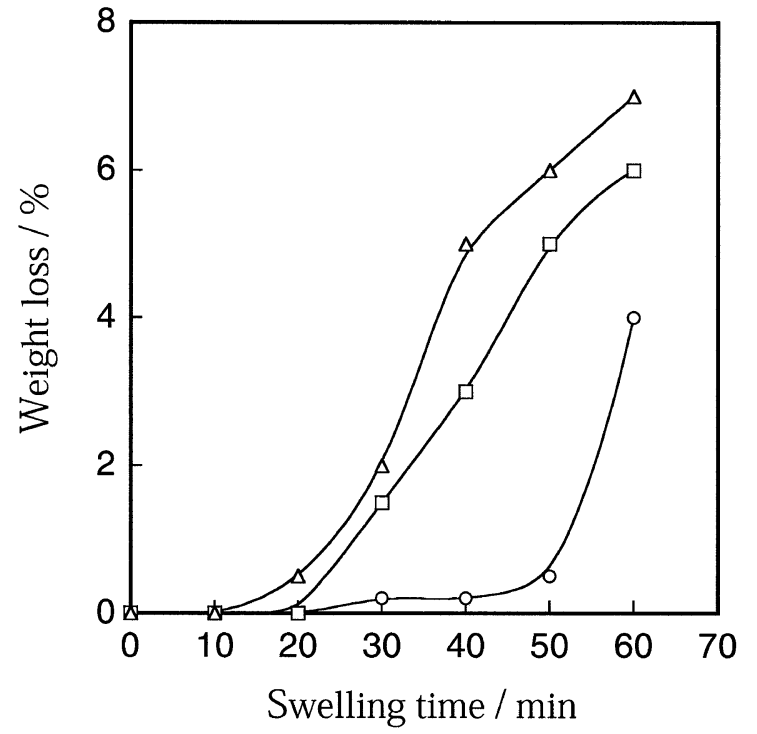

Figure 4. Weight loss for polyethylene specimens when swollen freely in cyclohexane-toluene mixture at a volume ratios of $0.5 / 9.5$ at different temperatures: $103^{\circ} \mathrm{C}(\bigcirc), 104^{\circ} \mathrm{C}(\square), 105^{\circ} \mathrm{C}$ $(\triangle)$.

and $35 \mathrm{~min}$, respectively. The subsequent experiments were carried out under these conditions.

\section{Swelling Behavior under Stress}

We have found that when a dumbbell-shaped specimen is elongated by applying a slight stress during the swelling process, the specimen's draw ratio for subsequent drawing is improved compared to the specimen prepared with no stress. The elongation and the ratio of the elongated length to the initial length of a specimen are termed "pre-drawing" and "pre-draw ratio", respectively. In the present study, we examined swelling behavior under different stresses. Typical examples of the obtained results are shown in Figure 5. The application of high stress $9.38 \times 10^{4} \mathrm{~kg} \mathrm{~m}^{-2}$ resulted in an elongation that started relatively early in the swelling. The initial quick rise of the curve slows down with swelling time. There is a distinct transition of the slope for the stress $9.38 \times 10^{4} \mathrm{~kg} \mathrm{~m}^{-2}$. The transition becomes less clear as the stress decreases. It is noteworthy that the pre-draw ratio for the specimen with swelling

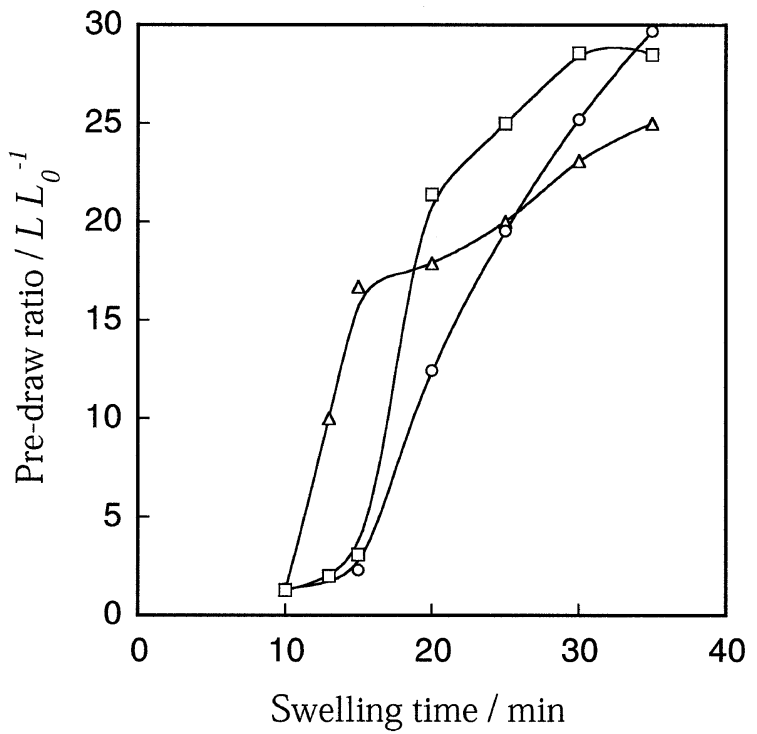

Figure 5. Plots of the pre-draw ratio against swelling time for polyethylene specimens swollen at $104^{\circ} \mathrm{C}$ under different stresses: $1.5 \times 10^{4}(\bigcirc), 4.63 \times 10^{4}(\square), 9.38 \times 10^{4} \mathrm{~kg} \mathrm{~m}^{-2}(\triangle)$.

time of $35 \mathrm{~min}$ assumed the largest value for the stress $1.5 \times 10^{4} \mathrm{~kg} \mathrm{~m}^{-2}$. The pre-draw ratios for swelling time of $35 \mathrm{~min}$ measured under different stresses are plotted against the stress in Figure 6. The pre-draw ratio increases rapidly with increasing stress and then gradually decreases. The optimal stress is $1.5 \times 10^{4} \mathrm{~kg} \mathrm{~m}^{-2}$. The corresponding curve in Figure 5 is smooth, indicating that when a curve is smooth, a larger pre-draw ratio can be attained, and there is thus an optimum value for the applied stress.

\section{Influence of the Pre-Draw Ratio on Draw Ratio}

Further experiments were carried out to examine how the pre-drawing influenced subsequent drawing. Dumbbell-shaped polyethylene specimens were swollen under the same conditions as those described above, and were elongated until specified pre-draw ratio was reached. Pre-drawn specimens under different stresses kept in glass tubes (Figure 2) were quenched rapidly to $-50^{\circ} \mathrm{C}$ for $2 \mathrm{~min}$, and then dried at room temperature for approximately $50 \mathrm{~min}$. They were then drawn in a polyethylene glycol bath kept at $115^{\circ} \mathrm{C}$. The 


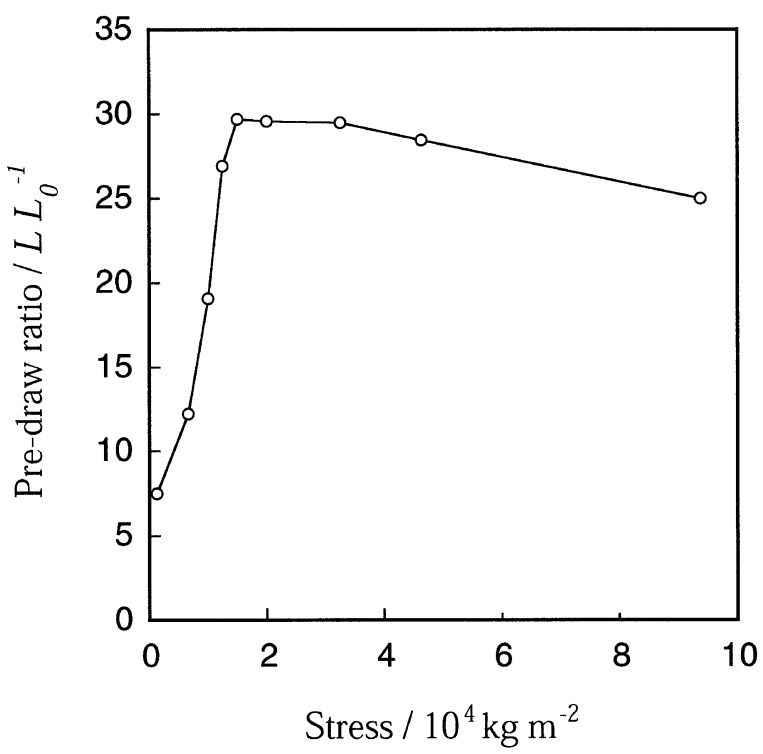

Figure 6. Plots of the pre-draw ratio at $104^{\circ} \mathrm{C}$ after a swelling time of $35 \mathrm{~min}$ against the applied stress.

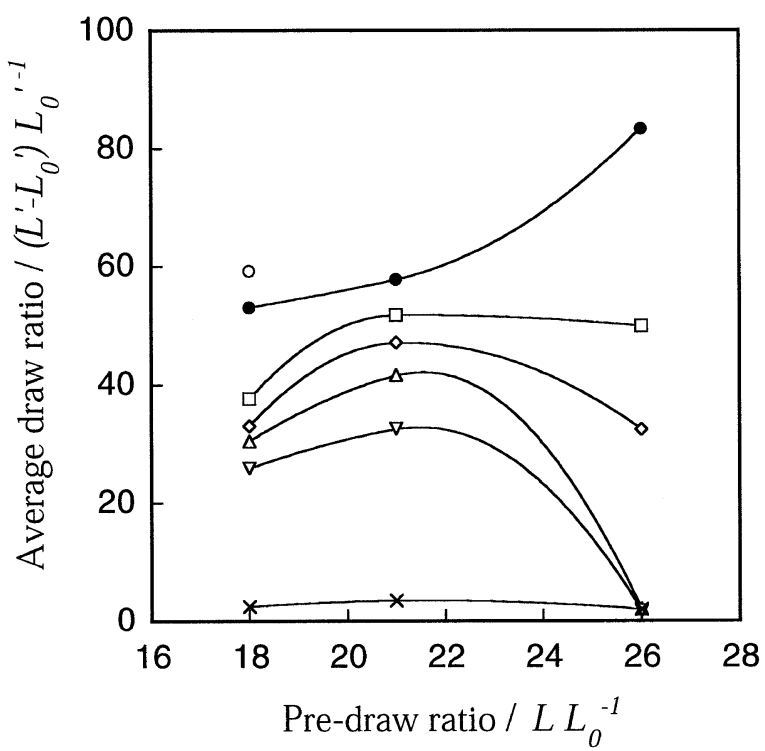

Figure 7. Plots of the average draw ratio against the pre-draw ratio for polyethylene specimens swollen at $104^{\circ} \mathrm{C}$ under different stresses: $1.13 \times 10^{4}(\bigcirc), 1.50 \times 10^{4}(\bigcirc), 3.25 \times 10^{4}(\square), 4.63 \times 10^{4}$ $(\diamond), 6.25 \times 10^{4}(\triangle), 7.75 \times 10^{4}(\nabla), 9.38 \times 10^{4} \mathrm{~kg} \mathrm{~m}^{-2}(\times)$.

draw ratios are plotted against the pre-draw ratios in Figure 7. Each plot is the average of 20 measurements. These draw ratios are the values at the instance when the specimens were torn apart. The specimen swollen under $9.38 \times 10^{4} \mathrm{~kg} \mathrm{~m}^{-2}$ could be hardly drawn for any pre-draw ratio. However, a decrease in the applied stress leads to an increase in the draw ratio, the appearance of a maximum, an upward shift of the maximum, and finally to a continuous increase in draw ratio. However, a further decrease in stress do not lead to a draw ratio beyond 18 , as no further elongation in the swelling process occurred. The specimen elongated to the predraw ratio of 26 under a stress of $1.5 \times 10^{4} \mathrm{~kg} \mathrm{~m}^{-2}$ was

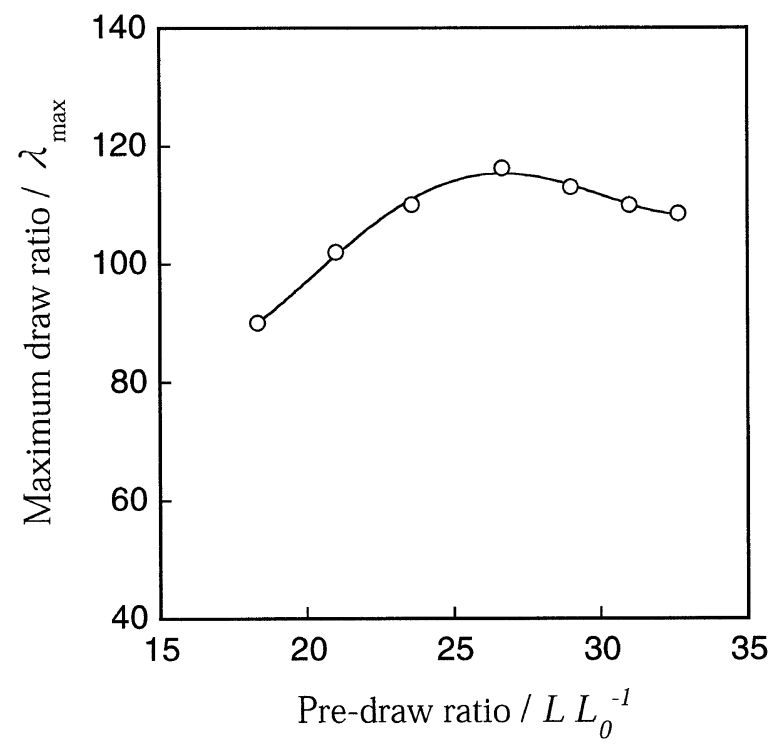

Figure 8. Plots of the maximum draw ratio against the predraw ratio for polyethylene specimens swollen at $104^{\circ} \mathrm{C}$ under a stress of $1.5 \times 10^{4} \mathrm{~kg} \mathrm{~m}^{-2}$.

found to be drawn to more than 80 times of the predrawn length.

To determine the optimal pre-draw ratio required to obtain stronger fibers, the relationship between the predraw and draw ratios for specimens swollen under a stress of $1.5 \times 10^{4} \mathrm{~kg} \mathrm{~m}^{-2}$ was studied. The obtained results are shown in Figure 8. The plots in the figure are the maximum draw ratios obtained in the experiment. The maximum draw ratio is found to peak at pre-draw ratio of about 26 , suggesting that a structure most suitable for drawing is established at this pre-draw ratio.

\section{Influence of the Residual Pre-Swelling Solvent in the Swelling Specimen on Drawing}

A specimen elongated to a pre-draw ratio of 26 under a stress of $1.5 \times 10^{4} \mathrm{~kg} \mathrm{~m}^{-2}$ was rapidly quenched to $-50^{\circ} \mathrm{C}$ for $2 \mathrm{~min}$, and it was dried at room temperature keeping the length constant. The drying behavior was monitored measuring the weight. The results are shown in Figure 9. The unit of the ordinate is the weight percentage of the swollen specimen with respect to the weight of solid polyethylene. The weight percent decreases rapidly with drying time, and then begins to flatten at about $50 \mathrm{~min}$. The rapid initial decrease is likely due to the evaporation of the solvent on the surface or in the vicinity of the surface of the swollen specimen, and the flattening to the gradual evaporation of the solvent deeper into the specimen.

To examine the relationship between the amount of the residual solvent and the drawing ratio, drawing of the polyethylene specimens, which were dried for different duration after swollen to the pre-draw ratio of 26 under a stress of $1.5 \times 10^{4} \mathrm{~kg} \mathrm{~m}^{-2}$, was carried out till 


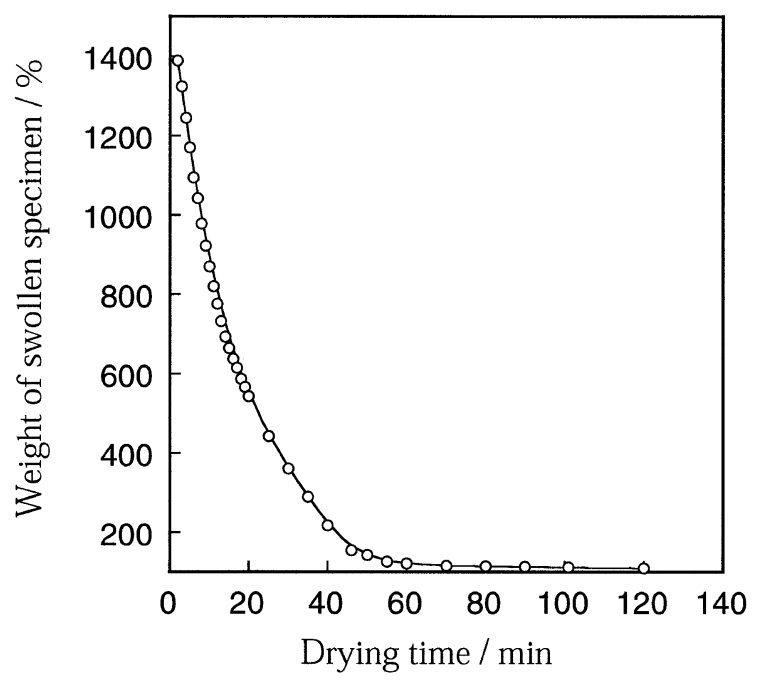

Figure 9. Weight of the swollen specimen in percentage with swelling time for the specimen swollen and elongated up to a predraw ratio of 26 at $104^{\circ} \mathrm{C}$ under a stress of $1.5 \times 10^{4} \mathrm{~kg} \mathrm{~m}^{-2}$. The specimen was dried upon exposure to the atmosphere at $20^{\circ} \mathrm{C}$.

they were torn apart. The averages of draw ratios are plotted against the content of polyethylene in Figure 10. Evidently, the draw ratio reaches a maximum at approximately $70 \mathrm{wt} \%$ of polyethylene content, then decreases gradually to about $90 \mathrm{wt} \%$, and increases again as it approaches the completely dry state. The polyethylene content at the peak corresponds to the value obtained for the drying time of $50 \mathrm{~min}$. The results show that an appropriate amount of the residual solvent in the specimen enables the specimen to be drawn smoothly. It is thought that in our experiment the solvent acted as a plasticizer in the initial stage of the drawing until it was squeezed out with the subsequent drawing. In the present study, the appropriate amount of the residual solvent in the drawing process was found to be about $30 \mathrm{wt} \%$.

Relationship between Mechanical Properties and the Pre-Draw Ratio

From these results we now focus on mechanical properties of drawn substrates which are prepared under stress $1.5 \times 10^{4} \mathrm{~kg} \mathrm{~m}^{-2}$, and with $30 \%$ residual solvent content. In Figure 11 the average tensile strengths are plotted against the pre-draw ratio. What is evident from the figure is that the tensile strength behaves similarly to the draw ratio in Figure 7. This indicates that a greater tensile strength is induced by a larger pre-draw ratio resulting from the reduction of entanglement. Plots for a pre-draw ratio of 26 at $7.75 \times 10^{4} \mathrm{~kg} \mathrm{~m}^{-2}$ and $6.25 \times 10^{4} \mathrm{~kg} \mathrm{~m}^{-2}$ are missing in Figure 11 since no fibrous substrates with measurable strength could be obtained. The maximum tensile strength in the experiment was $2.5 \mathrm{GPa}$ for a spec-

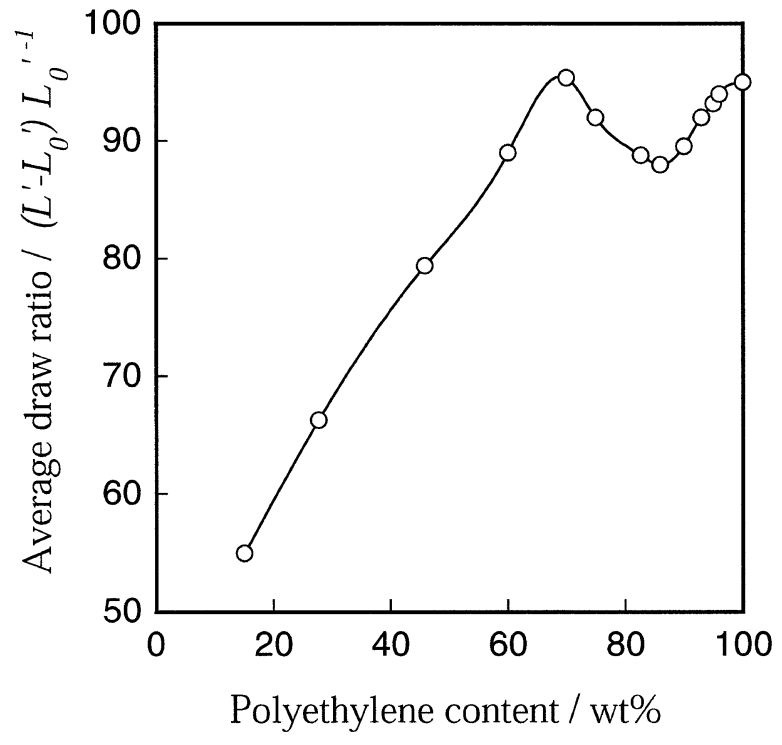

Figure 10. Relationship between the average draw ratio and the polyethylene content for the specimen swollen and elongated up to a pre-draw ratio of 26 at $104^{\circ} \mathrm{C}$ under a stress of $1.5 \times 10^{4} \mathrm{~kg} \mathrm{~m}^{-2}$.

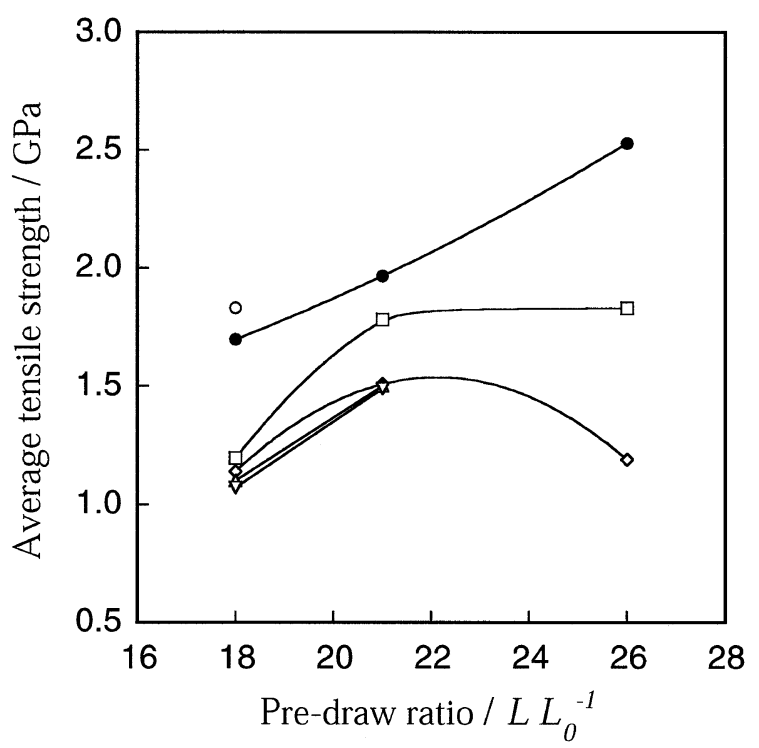

Figure 11. Relationship between the average tensile strength and the pre-draw ratio for polyethylene specimens swollen at $104^{\circ} \mathrm{C}$ under different stresses: $1.13 \times 10^{4}(\bigcirc), 1.50 \times 10^{4}(\bullet), 3.25 \times 10^{4}$ $(\square), 4.63 \times 10^{4}(\diamond), 6.25 \times 10^{4}(\triangle), 7.75 \times 10^{4} \mathrm{~kg} \mathrm{~m}^{-2}(\nabla)$.

imen swollen to a pre-draw ratio of 26 under a stress of $1.5 \times 10^{4} \mathrm{~kg} \mathrm{~m}^{-2}$. The tensile modulus is shown as a function of the pre-draw ratio in Figure 12. The result is analogous to that for tensile strength, indicating that a drawn substrate with higher tensile strength also has a corresponding higher tensile modulus. The maximum tensile modulus was found to be $80 \mathrm{GPa}$ for the specimen with maximum tensile strength. As it was determined that specimens swollen under a stress of $1.5 \times 10^{4} \mathrm{~kg} \mathrm{~m}^{-2}$ had the highest tensile strength as well as the highest pre-draw ratio, the mechanical properties of the specimens swollen under the same condi- 


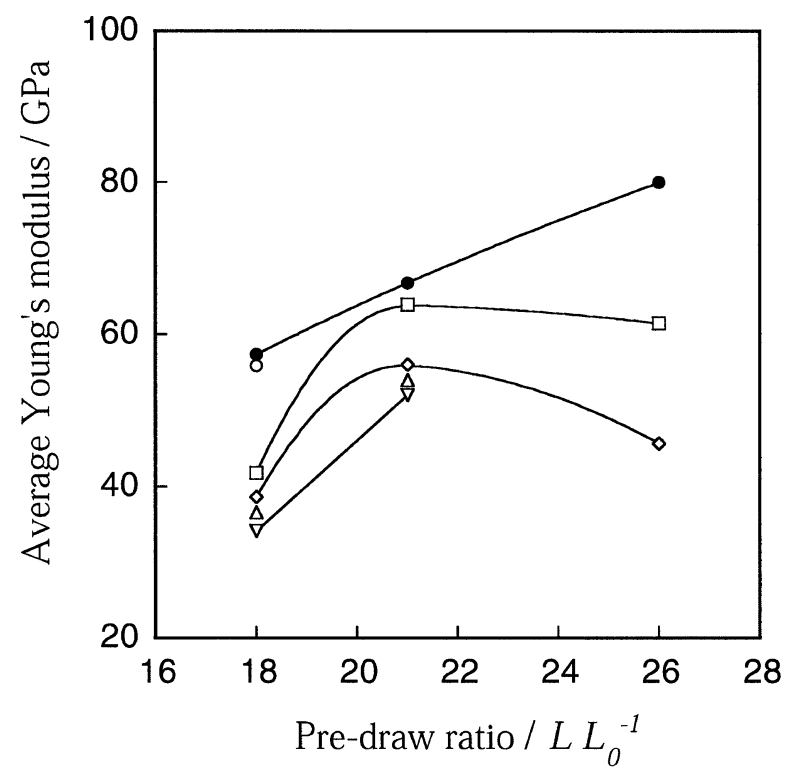

Figure 12. Relationship between the average Young's modulus and the pre-draw ratio for the polyethylene specimens swollen at $104^{\circ} \mathrm{C}$ under different stresses: $1.13 \times 10^{4}(\bigcirc), 1.50 \times 10^{4}(\bullet)$, $3.25 \times 10^{4}(\square), 4.63 \times 10^{4}(\diamond), 6.25 \times 10^{4}(\triangle), 7.75 \times 10^{4} \mathrm{~kg} \mathrm{~m}^{-2}$ $(\nabla)$.

tions were examined over a wide range of the pre-draw ratios. The maximum values of the tensile strength and the tensile modulus obtained for each pre-draw ratio are plotted in Figure 13. It can be seen from the figure that each result has a maximum in the vicinity of the predraw ratio of 26, which corresponds to the peak of the maximum draw ratio in Figure 8. From these results, the optimal pre-draw ratio in the swelling is determined to be 26 . The resulting maximum tensile strength and modulus are about $3.5 \mathrm{GPa}$ and $120 \mathrm{GPa}$, respectively.

\section{Influence of Pre-Drawing in Swelling on the Inner} Structure of Swollen Polyethylene Specimens

Although the effect of pre-drawing on drawing is clarified by the examinations in the preceding sections, the inner structural effect of pre-drawing on the drawability of the swollen substrates remains to be studied. Therefore, the crystallinity of specimens swollen under different stresses ranging from $1.5 \times 10^{4} \mathrm{~kg} \mathrm{~m}^{-2}$ to $9.38 \times 10^{4} \mathrm{~kg} \mathrm{~m}^{-2}$ was measured by the DSC method. Samples for the measurement were prepared by freezedrying specimens quenched at $-50^{\circ} \mathrm{C}$ after swelling. The degrees of crystallinity thus obtained fell between 0.46 and 0.50 , which were in practice the same considering the experimental error. Accordingly, it is thought that pre-drawing has no influence on the crystallinity of the specimens.

The orientation of polyethylene chain molecules in uniaxially deformed samples with rotational symmetry around the draw direction is known to be adequately characterized by the absorbances $A_{\|}$and $A_{\perp}$ of polar-

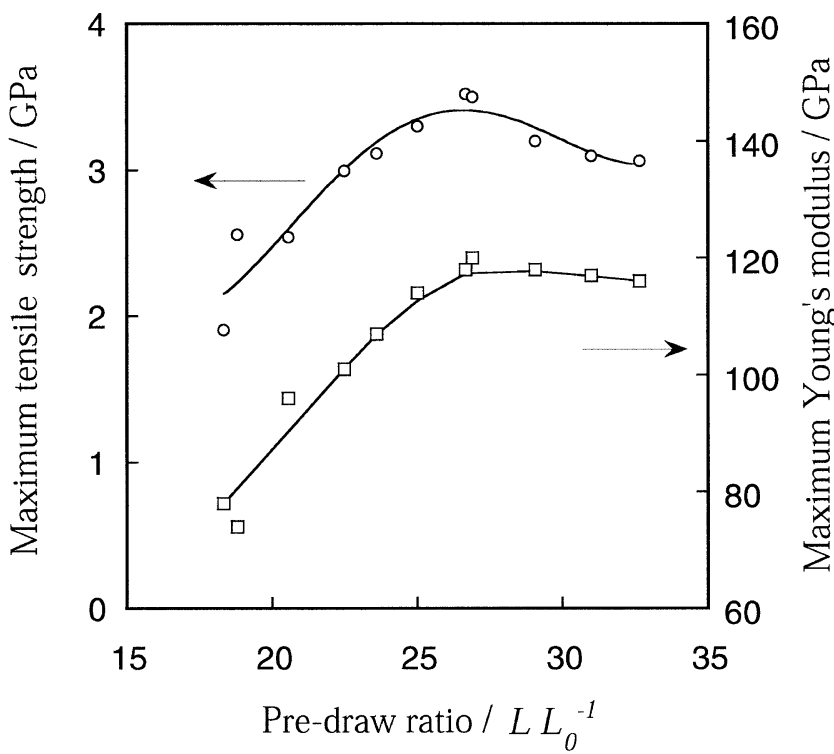

Figure 13. Plots of maximum tensile strength $(\bigcirc)$ and maximum Young's modulus ( $\square$ ) against the pre-draw ratio for the polyethylene specimen swollen at $104^{\circ} \mathrm{C}$ under a stress of $1.5 \times 10^{4} \mathrm{~kg} \mathrm{~m}^{-2}$.

ized radiation parallel and perpendicular to the draw direction, respectively. ${ }^{10-12}$ The dichroic ratio $D$ is defined as

$$
D=A_{\|} / A_{\perp}
$$

For the swollen substrates, the dichroism of the absorption band at $1894 \mathrm{~cm}^{-1}$ was a combination of crystalline $\mathrm{CH}_{2}$ rocking modes measured by polarized FTIR method. This dichroism has been found to approach zero with increasing draw ratio. ${ }^{12}$ The obtained results are plotted against the applied stress in Figure 14. The dichroic ratio at relatively low stresses shows values larger than 1, but an increase in stress leads to a decrease in the ratio, and at $9.38 \times 10^{4} \mathrm{~kg} \mathrm{~m}^{-2}$ the dichroic ratio decreases to less than 1 . The maximum dichroic ratio was obtained for samples swollen under a stress of $1.5 \times 10^{4} \mathrm{~kg} \mathrm{~m}^{-2}$. If the polyethylene chain in the crystalline form was oriented completely parallel to the elongation axis, the absorbance $A_{\|}$parallel to the elongation axis would be zero. In such a case, the dichroic ratio $D$ approaches zero. In contrast, if the polyethylene chain in the crystalline form is oriented completely perpendicular to the elongation axis, the absorption $A_{\perp}$ perpendicular to the elongation axis would be infinitesimal. Then, the dichroic ratio $D$ would approach infinity. In a disoriented substrate, the dichroic ratio equals 1 . Accordingly, the fact that a dichroic ratio in the substrate swollen under a stress of $1.5 \times 10^{4} \mathrm{~kg} \mathrm{~m}^{-2}$ is greater than 1 indicates that the probability for the folded polyethylene chains to be aligned perpendicular to the elongation axis is somewhat higher than that to be aligned parallel. This result indicates that the im- 


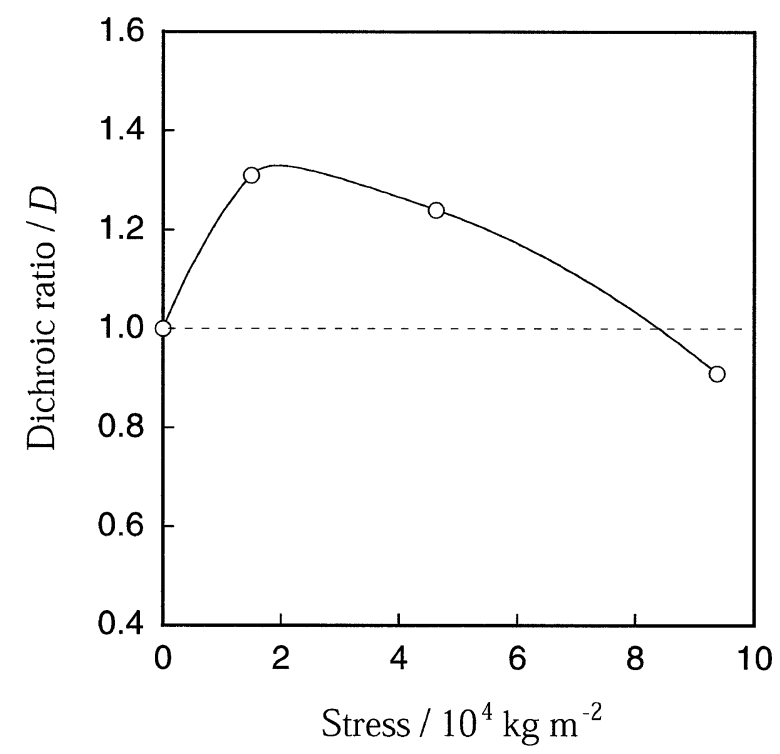

Figure 14. Relationship between the dichroic ratio on the basis of an absorption band $1896 \mathrm{~cm}^{-1}$ assigned to a combination of crystalline $\mathrm{CH}_{2}$ rocking modes and the stress applied in swelling. All the polyethylene specimens were swollen at $104^{\circ} \mathrm{C}$ and elongated up to 26 times.

proved disentanglement resulting from a suitable elongation due to stress in the swelling process leads to an alignment of polyethylene chains in crystallites predominantly perpendicular to the elongation direction.

Taking this result and the results regarding drawability described above into account, we propose schematic model shown in Figure 15. As swelling under an appropriate stress enables smooth elongation, it induces a reduction in the entanglement-density in swollen specimens. In the swelling process, the folded chains in crystallites align perpendicular to the elongation direction, enabling ultra-drawing in subsequent drawing processes. In contrast, when swelling occurs under relatively high stress, the substrate is elongated forcefully before sufficient swelling occurs, and consequently the reduction in the entanglement-density of the swollen structures is hindered. Accordingly, the drawability becomes relatively low.

To examine the changes in micrometer- and submicrometer-scale structures with swelling under different stresses, SEM observations were carried out. SEM specimens were prepared by depositing gold, under a vacuum below $10^{-5}$ Torr, on freeze-dried substrates treated with fuming nitric acid for $8 \mathrm{~h}$. SEM images are shown in Figures 16a, b, and c, for specimens prepared from swollen polyethylene substrates under stresses of $1.5 \times 10^{4} \mathrm{~kg} \mathrm{~m}^{-2}, 4.63 \times 10^{4} \mathrm{~kg} \mathrm{~m}^{-2}$, and $9.38 \times 10^{4} \mathrm{~kg} \mathrm{~m}^{-2}$, respectively. Figure 16a shows that fibrillar textures which are composed of the aggregates of the crystallites interconnected by tie molecules as in Figure 15 are oriented slightly parallel to the elon-

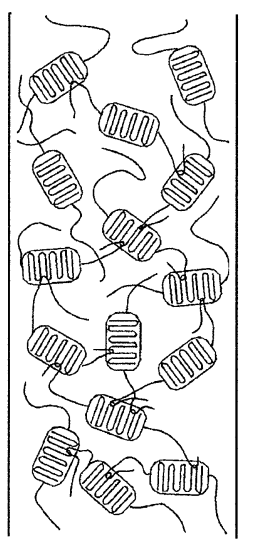

(a)

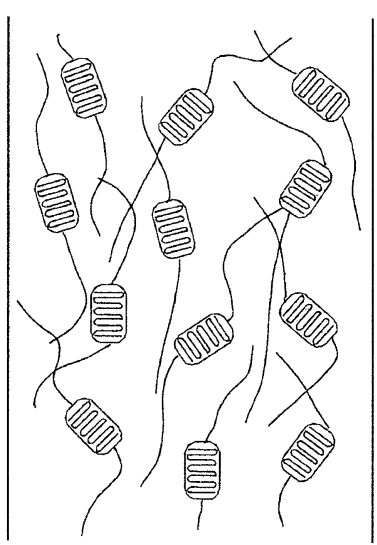

(b)
Figure 15. Schematic diagram of swell-elongation polyethylene. (a) The polyethylene prior to swelling, (b) The polyethylene elongated under appropriate stress in the swelling process.

gation direction. In Figure $16 \mathrm{~b}$ of the substrate under an increased stress, an apparent orientation of the fibrillar textures in the elongation direction can be seen. In Figure $16 \mathrm{c}$ of the substrate under much higher stress, it can be seen that a relatively nonporous structure has been formed with much greater overlap between fibrillar textures. These results demonstrate that in order to develop higher drawability it is necessary to adjust the stress to elongate swollen specimens so that the aggregates of lamellar crystals are held loose.

\section{CONCLUDING REMARKS}

By using cyclohexane-toluene mixture in volume ratios of 0.5 to 9.5 , polyethylene sheets could be swollen to a significant extent at relatively low temperatures. The polyethylene specimen swollen under an appropriate stress was found to be drawn very highly in subsequent drawing process. In addition, it was found that the application of the optimal stress in the swelling process led to the reduction in polyethylene chain entanglement and to the improvement of the orientation of the fibrillar textures in the elongation direction without recrystallization. There is a close connection between the pre-drawing ratio and drawing ratio. It was found that subsequent drawing could be carried out smoothly when the specimens had been pre-drawn to 26 times of the original length. The highest drawability in the swollen polyethylene specimen was found when a $30 \mathrm{wt} \%$ solvent was left in the specimen. Under the most suitable conditions we were able to achieve a maximum tensile strength and modulus of $3.5 \mathrm{GPa}$ and $120 \mathrm{GPa}$, respectively. These are values equivalent to or greater than those obtained by gel drawing. More importantly, this improved swell-drawing method re- 

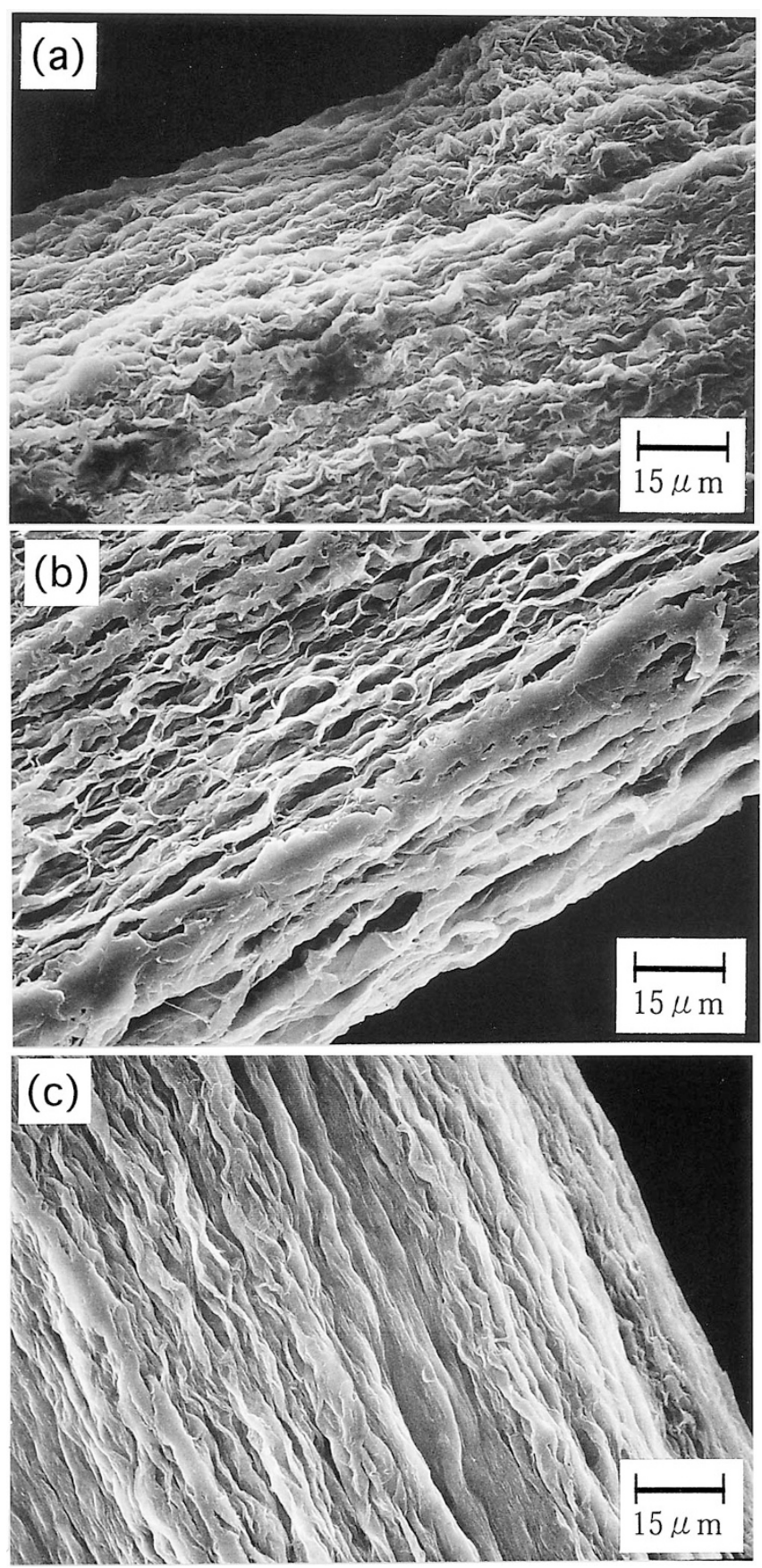

Figure 16. SEM images of the polyethylene specimen treated with fuming nitric acid for $8 \mathrm{~h}$ after being elongated under different stresses in swelling: (a) $1.50 \times 10^{4} \mathrm{~kg} \mathrm{~m}^{-2}$, (b) $4.63 \times 10^{4} \mathrm{~kg} \mathrm{~m}^{-2}$, (c) $9.38 \times 10^{4} \mathrm{~kg} \mathrm{~m}^{-2}$. quires no dissolution of UHMWPE to draw, and hence opens up a number of possibilities for further enhancements of the performance of polyethylene fibers. For instance, the results in the present study suggest that the method could be applicable to polyethylene of even larger molecular weight.

At present we are applying the method to polyethylene with $M_{\mathrm{w}}$ of about $3.30 \times 10^{6}$, and examining the possibility of achieving higher drawability. Details on these will be reported in near future.

Acknowledgment. The authors wish to express their gratitude to Professor T. Kanamoto of Science University of Tokyo for helpful discussions. This work was supported in part by a Grant-in-Aid for COE Research (10CE2003) by the Ministry of Education, Culture, Sports, Science and Technology of Japan.

\section{REFERENCES}

1. M. R. Mackley and S. Solbai, Polymer, 28, 1115 (1987).

2. J. Smook, J. C. Torfs, P. F. van Hutter, and A. J. Pennings, Polym. Bull., 2, 293 (1980).

3. P. J. Barham and A. Keller, J. Mater. Sci., 15, 2229 (1980).

4. K. Ishikawa, K. Miyasaka, M. Maeda, and M. Yamada, J. Polym. Sci., A-2, 7, 2029 (1969).

5. K. Furuhata, T. Yokokawa, and K. Miyasaka, J. Polym. Sci., Polym. Phys. Ed., 22, 133 (1984).

6. P. Smith and P. J. Lemstra, J. Mater. Sci., 15, 505 (1980).

7. P. Smith and P. J. Lemstra, J. Polym. Sci., Polym. Phys. Ed., 19, 877 (1981).

8. P. Smith, P. J. Lemstra, J. P. L. Pijpers, A. M. Kiel, Colloid Polym. Sci., 259, 1070 (1981).

9. T. Ohta, T. Wachi, T. Nagai, A. Takada, Y. Ikeda, T. Ohtsubo, and A. Kawaguchi, Polymer, 34, 4863 (1993).

10. T. Ohta, A. Takada, T. Yamamura, A. Kawaguchi, and S. Murakami, Polymer, 36, 2181 (1995).

11. P. Gao, M. R. Mackley, and T. M. Nicholson, Polymer, 31, 237 (1990).

12. T. Ohta, Sen'i Gakkaishi, 40, 407 (1984).

13. S. Krimm, Fortschr. Hochpolym., 2, 51 (1960).

14. R. S. Snyder, J. Chem. Phys., 47, 1326 (1967).

15. W. Grenz and A. Peterlin, J. Polym. Sci. A-2, 9, 1191 (1971). 